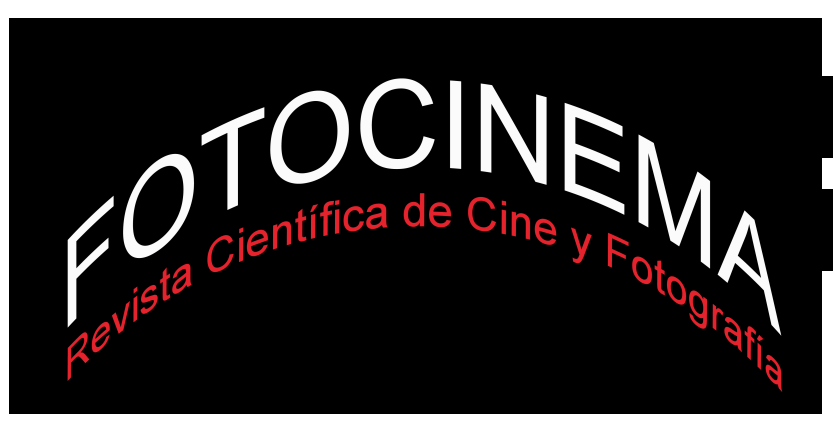

\title{
FOTOGRAFÍA DE LARGA EXPOSICIÓN Y CINE ESTRUCTURAL: UNA REFLEXIÓN EN TORNO AL LOOP
}

\section{LONG EXPOSURE PHOTOGRAPHY AND STRUCTURAL FILM : A REFLECTION ON LOOPS}

\author{
Ricardo Roncero Palomar \\ Universidad Rey Juan Carlos, España \\ ricardo.roncero@urjc.es
}

\section{Resumen:}

La posibilidad de reflejar el tiempo en la escena fotográfica tiene unos condicionantes estéticos derivados de una necesidad técnica, la apertura y clausura del obturador. Esta guillotina temporal es la encargada de seleccionar el fragmento de tiempo que queremos registrar, de tal manera que las acciones ocurridas durante este periodo obtendrán una representación gráfica. Este articulo trata de reflexionar sobre estas representaciones y a su vez de enlazarlas con la figura del sample y del loop. Se trataría de vincular la posibilidad de representación del tiempo ligado al movimiento a traves de la fotografía, con la idea de repetición temporal que aporta el loop. Elemento que fue desarrollado especialmente por el cine estructural durante la década de los 60. Para ello se estudiarán diversos ejemplos, tanto fotográficos como cinematográficos, de obras que abordan la cuestión de la representación temporal y se relacionarán con documentos escritos sobre el tema.

\begin{abstract}
:
The possibility to reflect time in the photographic medium has certain aesthetic constrains derived from a technical necessity; the opening and closing of the shutter. This temporary guillotine is responsible for selecting the fragment of time that we want to capture, in a way that the actions that occurred during this period will obtain a graphical representation. This article intends to reflect on these representations and link them with the figure of the sample and the loop. It attempts to link the possibility of representing time, associated to movement through photography, with the idea of temporal repetition of the loop, element which was specially developed by the Structural Cinema movement during the 6o's. To find an answer, photographic and cinematographic examples that analyzed the issue of temporary representation will be studied and will be related with written documents about the subject.
\end{abstract}

\section{Palabras clave:}

Fotografía; larga exposición; cine estructural; loop; sample; tiempo.

\section{Keywords:}

Photography; Long-exposure; Structural Film; Loop; Sample; Time. 


\section{Introducción}

Con el invento de la fotografía, el ser humano consiguió fijar la luz y las sombras de manera mecánica, construía ese lápiz de la naturaleza (Talbot, 2003, p. 49) capaz de capturar una imagen partiendo de un modelo real. Fotografías que, en sus inicios, ayudaban el dibujante pero que, con posterioridad, acabaron siendo imagen de la representación de lo real, la escena en sí misma, lo literal (Barthes,1986 p. 13). Esa captura iba acompañada inexcusablemente de dos realidades, un espacio y un tiempo concreto, indisolubles pero variables. Ambos factores quedaban convertidos en imagen fija gracias a un dispositivo que, mediante un mecanismo, las transformaba en escenas plásticas, imágenes tangibles. De estos dos ejes, el tiempo y el espacio, esta investigación se centrará en la representación de la primera: el tiempo.

Al contemplar una fotografía de la colección Theatres (1978-1993), de Hiroshi Sugimoto, tenemos la sensación de estar percibiendo un instante concreto, un breve momento en el cual la cámara de gran formato captó la sala cinematográfica presidida por una gran pantalla blanca que emite luz. Una inquietante pero serena estampa que, en realidad, no responde a un breve instante; el obturador se mantuvo abierto durante todo el tiempo en el que transcurrió la película que se estaba proyectando. Un periodo de tiempo considerable que quedó retenido en el negativo y que responde a una representación temporal en la cual sucede un proceso, un cambio en la escena fotografiada. Es un periodo de tiempo concreto que el espectador percibe en un solo instante, pero que en realidad se trata de la suma de muchos.

Este articulo propone una reflexión sobre la idea de tiempo utilizando la idea de loop como figura y nexo entre la imagen fotográfica de larga exposición y la cinematográfica, en concreto de las obras realizadas bajo el umbral del cine estructural.

Una de las características que puede incluir el cine estructural es su construcción mediante loops. Fragmentos de películas que suelen 
corresponder con un periodo temporal y espacial conciso en el que sucede una acción y que son presentados de manera continua, a modo de repetición constante. La idea de fragmento temporal es la misma en la fotografía que en el cine, aunque su representación muy diferente.

La posibilidad de fijar el tiempo en el medio fotográfico es muy diferente que en el cinematográfico. Nos encontramos ante distintos medios de representación. En uno, la imagen es concreta, una unidad. En el otro la sensación de movimiento está causada por la suma de numerosos instantes. Sin embargo podemos encontrar ideas comunes en las cuales estos conceptos se aproximan.

\section{Marco teórico y metodología}

Es importante incidir que esta investigación estudiará piezas visuales obtenidas mediante prácticas artísticas. La puntualización es importante porque, dentro del proceso documental, la libertad plástica del realizador de las imágenes está acotada a un proceso de informativo ${ }^{1}$. Sin embrago, en la práctica artística las posibilidades plásticas son mayores al no tener que adaptarse a un proceso concreto comunicacional o científico, es decir, a la ilustración de un hecho concreto de manera que sea asimilable directamente por el espectador o servir de herramienta para comunicar ciencia. Esta libertad plástica es la que permitirá obtener una representación temporal más amplia y diferente al modelo documental.

Las preguntas que se plantean son ċcómo puede representar el tiempo la fotografía? ¿qué capacidad tiene para reproducir un momento determinado? o ¿de qué manera el espectador es capaz de decodificar las imágenes para entender el proceso de representación temporal?

\footnotetext{
${ }^{1}$ Aunque la representación temporal en la fotografía documental está muy ligada a la idea de imagen definida y congelada en el tiempo podemos encontrar algunos ejemplos en los que la acción temporal se desarrolla en periodos más extensos apareciendo efectos de estelas e imágenes poco definidas como ilustran algunas fotografías de Paolo Pellegrin o Raghu-Rai.
} 
En el nivel técnico, el encargado de diseccionar un periodo concreto en una fotografía es el obturador. Una cortina opaca que permite que el sensor o la película esté en contacto con la luz que proyecta la escena seleccionada por el fotógrafo. Cuando pulsamos el disparador de la cámara, el obturador se abre durante un tiempo preciso y justo para que, si la luz se ha medido correctamente en relación a la sensibilidad y al diafragma, el material fotosensible capte la luz de la escena de manera correcta, iniciando el proceso de representación de la misma.

Thierry de Duve distingue dos tipos de imágenes en relación al tiempo representado: aquellas que considera "instantáneas, de la que el reportaje deportivo nos ofrece tantos ejemplo" y "el posado (...) ofrecido para su contemplación menos como un acontecimiento notable y fechado que como una duración perenne, evocable a voluntad" (de Duve 2013, pp. 67-68). Dentro de la primera distinción, encontramos la gran mayoría de las imágenes realizadas en la actualidad. Son imágenes que captan un momento exacto, un tipo de fotografía para la que están preparadas las cámaras automáticas, incluídas las de los móviles $^{2}$, y hacia la cual la industria fotográfica sigue moviéndose, a la caza del obturador más rápido, películas o sensores de mayor luminosidad o flashes más potentes, capaces de congelar el instante más preciso. La instantáneidad está relacionada con la idea del momento decisivo desarrollado por Henri Cartier-Breson, "para mi la fotografía es el reconocimiento simultáneo, en una fracción de segundo, de la significación de un hecho con la organización precisa de las formas que dan a ese hecho una expresión propia” (Cartier-Breson, 2003). Se trata de la imagen congelada, la fotografía que nos permite analizar el movimiento, detener el tiempo en una fracción concreta.

Frente a la idea de fotografía instantánea de De Duve, el filósofo belga presenta otra alternativa, otro tipo de imagen que no goza en la actualidad de tanto uso pero que permite una captura de tiempo diferente lejos de la

${ }^{2}$ Flickr la mayor comunidad de fotógrafos en la Red que permite la exhibición y venta de fotografía indica en octubre de 2015 que las cámaras más usadas por los fotógrafos de su portal son las del teéfono móvil Iphone. Disponible en: https://www.flickr.com/cameras. 
imagen congelada, "desde el punto de vista plástico el ideal de la instantánea es la nitidez. Sin embargo hay toda una vertiente de la fotografía que propugna lo desenfocado, lo movido y lo barrido, porque estos procedimientos permiten representar el movimiento" (de Duve 2013, p. 73). $\mathrm{Al}$ desaparecer ese instante fotográfico, esa inmediatez, aparece la necesidad de reflejar un mayor paso del tiempo en la imagen. Esta posibilidad puede traernos dos tipos de fotografías; la imagen posado a la que se refiere de Duve, que tuvo su época dorada durante los retratos de los primeros años de la fotografía -cuando los tiempos de exposición durante los retratos se alargaban debido a la baja sensibilidad del material fotográfico y el sujeto debía permanecer inmóvil para obtener una imagen detallada del mismo-. O, por otro lado, podemos encontrar la imagen en la cual se desarrolla una acción durante su proceso de captación. Este tipo de representación será el que se estudie en esta investigación. Son imágenes que presentan un acto de temporalidad variable, y que es recogido entre la apertura y clausura del obturador. Desaparece pues la idea del instante decisivo, pero desaparece también la imagen congelada, perfecta, el tipo de fotografías que inundan nuestros medios de comunicación. Nos encontramos con una imagen que contiene una lectura diferente, con frecuencia borrosa, poco definida que, a menudo, presenta estelas de movimiento de una manera que el ojo humano es incapaz de ver fuera de la realidad fotográfica. Una imagen que enlaza con la idea de jeroglífico desarrollado por Barthes, entendida como una imagen "en la que se pueda leer de una sola ojeada (de un solo golpe de vista, si se trata de teatro o cine), presente, pasado y futuro, o sea el sentido histórico del gesto representado" (Barthes, 1986, p. 96). Imágenes que el espectador puede no entender, ya que el proceso, la acción temporal que presenta la fotografía, puede estar codificada de tal manera que resulte complicada su comprensión. Como Barthes indica, la lectura de la fotografía por parte del lector es histórica, dependerá de sus conocimientos para poder descifrarla (Barthes, 1986, p. 24) y entender la representación gráfica temporal utilizada en la fotografía. Esta idea es desarrollada y analizada por Schaeffer, en ella indica que en la recepción de la imagen invervienen dos factores, las reglas 
comunicacionales y lo que denominó “saber lateral”, es decir, aquellas informaciones que el espectador añade con su experiencia. (Schaeffer, 1990, p. 79).

Este segmento temporal se vincula con la idea de loop. Podemos definirlo como un fragmento cinematográfico o sonoro de duración breve repetido en continuidad. Ese fragmento seleccionado y que es repetido formando el loop recibirá en esta investigación el nombre de sample. Es habitual que ese fragmento tenga una continuidad espacial y temporal. Si reducimos el sample a una sola imagen, por ejemplo compilando todos los fotogramas en uno solo, obtendríamos una fotografía similar a las imágenes de larga exposición, una imagen que representa un una acción trascurrida en un periodo de tiempo con un principio y un fin determinado. Se trataría de una imagen con una representación temporal más larga que lo habitual, pero en ningún caso sería equiparable al loop.

La necesidad de hacer el tiempo visible en la fotografía, de su representación visual y animada, fue uno de los factores que impulsaron el nacimiento del cinematógrafo. Prácticas como las fotografías de larga exposición o las cronofotografías, imágenes donde se desarrollaba una acción en una sola toma gracias, por ejemplo, al flash, habían comenzado este proceso. El cine conseguiría representar el movimiento gracias a una rápida sucesión de imágenes en el tiempo y a los efectos de la persistencia retiniana. Fotografía y cine comparten una misma tecnología de captación de imagen pero con métodos de representación diferentes, "el cine, con todo rechaza la petrificación de la instantánea ocultando su propia dependencia de la imagen inmóvil, el fotograma" (Doanne, 2010, p. 64). No podemos igualar la representación temporal en la fotografía y en cine; mientras el segundo se desarrolla en el tiempo de manera concreta, la fotografía no tiene un instante de visualización concreto, dependerá del espectador el tiempo que decida observarla.

Esta idea de loop se materializa como característica formal dentro de un tipo de cine clasificado y desarrollado por P. Sidney como cine estructural, que se 
desarrollaría durante los años sesenta coincidiendo con la popularidad del cine underground. El cine estructural perpetúa la batalla al cine comercial iniciada con el underground, pero desde perspectiva diferente. La investigación en la experimentación cinematográfica llevó a algunos cineastas a abandonar la narración, a desplazar las orientaciones más líricas, para centrar sus obras en aspectos mucho más formales e intrínsecos a la materia puramente cinematográfica, como son el acetato fílmico, la luz, el tiempo o el proceso cinematográfico en sí. Se trata un cine de estructuras que deja de lado la narración, donde no existe un desarrollo tipo presentación-nudo-desenlace al uso, ni siquiera un clímax en la obra. En este caso, todo queda supeditado a la forma de la película, su estructura es el motivo principal de la obra. "El cine estructural insiste en su forma y que el contenido sea mínimo de manera subsidiaria a la idea." (Sitney, 2000, p. $327)$.

El cine estructural rechaza la idea del cine como evasión o como sueño, sitúa al espectador ante un acto de lectura de las imágenes, muchas veces en el sentido más literal. A pesar de que existen referencias de piezas similares a las denominadas estructurales desde principios de los años veinte, obras como Emak Bakia (1926) de Man Ray y Ballet Mecánico (1924) de Fernand Léger -ambas cuentan con repeticiones de la misma secuencia, una de las características que se asociarán a este tipo de cine-, sus referentes más inmediatos se encuentran en algunas de las primeras piezas cinematográficas de Andy Warhol. En concreto en obras como Kiss (1963), Blow Job (1963), Sleep (1963) o Empire (1964).

Para este estudio se utilizará el texto que Adams Sitney publicó en el invierno de 1969, titulado "Structural film", y que se trata de una revisión del publicado en el verano del mismo año en la revista Film Culture. En el artículo, además de bautizar esta nueva tendencia cinematográfica -en la que la forma es más importante que la narración- como cine estructuralista, nombra algunas características plásticas que se habían hecho muy habituales en estas piezas y que ayudan a identificarlas. Todas no tienen por qué 
coincidir en un mismo film. De hecho, en algunas piezas importantes de este movimiento no llega a aparecer ninguna3. Sitney especifica cuatro características básicas:

a) Posición de cámara fija. El plano permanece fijo a la vista del espectador, aunque no tiene por qué ser estático.

b) El efecto de parpadeo en la proyección.

c) La repetición en bucle (loop)

d) El registro o grabación de imágenes directamente de la pantalla, de un televisor o de una proyección.

Se trata de un cine que opera ante realidades percibidas y realidades propias de un medio, un cine que profundiza en el análisis de los procesos de reproducción y percepción (Collado, 2012). De las cuatro características presentadas por Sitney, este estudio trabajará con obras que presenten la tercera, la repetición en bucle de fragmentos de película, la más directa en relación a la representación temporal, abarcando también algunas piezas más actuales creadas fuera del amparo del movimiento, pero que utilizan algunas de sus características.

\subsection{Prolongando el tiempo de exposición}

En 1838 Daguerre captó desde su estudio la primera imagen fotográfica en la que aparecía un ser humano. El daguerrotipo, realizado sobre el Boulevard du Temple, presenta una imagen desértica de la escena. El elevado tiempo de exposición que requería la imagen borró todo elemento que en ese fragmento temporal se estuviera moviendo, todo excepto un limpiabotas y su cliente. Daguerre sabía que esto pasaría, que cualquier figura que estuviese moviéndose desaparecería de la imagen final como atestigua la otra imagen que tomó desde la misma perspectiva. Por ello no sería extraño que, como sugiere Fontcuberta, las figuras que están quietas estuviesen ahí por deseo

\footnotetext{
3 La obra La Région centrale (1971) de Michael Snow no posee ninguna de las cuatro características.
} 
expreso de Daguerre (Fontcuberta, 2010, p. 106). El hecho es que en estas dos personas podemos apreciar la huellas de un tiempo, el tiempo exacto en el que la luz se puso en contacto con la superficie fotosensible del daguerrotipo. El torso del hombre y las manos del limpiabotas desaparecen, solo vemos su estela, una metáfora visual del movimiento, de un periodo de tiempo concreto. Esta primera estela, que ilustra el movimiento realizado durante la captura fotográfica, se repetirá de manera constante durante toda la historia de la fotografía. Se trata de una forma gráfica que muestra un periodo de tiempo, un momento prolongado de una manera que el ojo humano es incapaz de registrar en la realidad. Como se citaba al principio, Sugimoto utilizó esta idea de captación prolongada durante su serie Theatres (F1). En ella realizó fotografías a salas cinematográficas y autocines utilizando como tiempo de obturación la duración total de la película. El resultado es todo un film concentrado en una imagen, una sucesión de luz reflejada durante un periodo de más de una hora a un golpe de vista, una pantalla totalmente blanca, que irradia luz e ilumina una sala que en realidad está a oscuras. Tan solo en algunas fotografía 4 de los cines vemos la estela de los espectadores, o el movimiento de los árboles y aviones en los autocines. Si suprimiéramos estas pistas, el espectador podría contemplar esta fracción temporal sin saberlo. Sería fácil pensar que todo es fruto de un instante ya que todo permanece quieto, inerte, pero la realidad es diferente, se encuentra ante la captación del tiempo cinematográfico, la imagen en movimiento dentro de una imagen fija, que irónicamente queda representada como una imagen en blanco, representación de la nada en la suma sustractiva de color y del todo en la aditiva.

4 Podemos ver algunos de estos efectos en Union City Drive-In, Union City, 1993 o Winnetka Drive-In, Paramount, 1993; 

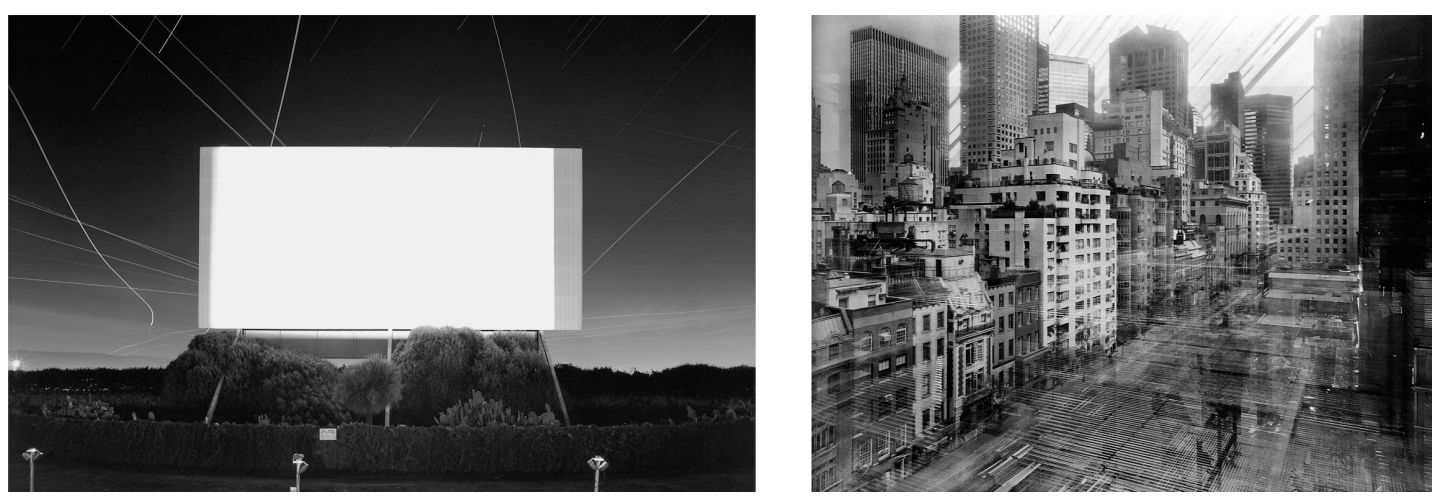

El fotógrafo alemán Michael Wesely también trabaja con esta idea de grandes tiempos de exposición, en concreto en su serie Open Shutter, (F2) realizada sobre la reforma arquitectónica que sufrió el MoMA entre 2001 y 2004. Durante estos tres años, el obturador de las inmóviles cámaras de Wesely registró todo el proceso de transformación exterior del museo. Capas y capas de elementos arquitectónicos se acumulan en una sola imagen para condensar el proceso de transformación del popular edificio durante esos tres años. Un sample temporal que se podría parecer que se convierte en loop cada vez que el espectador ve la imagen, la misma acción, el mismo espacio de tiempo en el que vemos el mismo proceso, de golpe, sin un principio y un final. De hecho, si no fuera por que los procesos de construcción y demolición son diferentes, no sabríamos si el edificio sufre un proceso de ampliación o de reducción de su infraestructura.

A medida que se alarga el tiempo de exposición y se altera la posición de la cámara durante la captación de la escena la idea de imagen como reflejo de una realidad se va perdiendo, muta hacia otra realidad únicamente visible a través de la fotografía. La imagen real va dejando su impronta sobre el material fotosensible, transformándolo en una representación más cercana a la iconografía abstracta que a una imagen figurativa. Se pierden los referentes reales y la luz crea dibujos en el espacio a medida que se prolonga el tiempo de exposición. El trabajo de Hanna Hänninen The New landscapes (2004-2006) (F3) desarrolla esta idea. Las imágenes muestran líneas irregulares sobre fondos planos o degradados, fotografías de paisajes urbanos en las que ha desaparecido todo elemento reconocible. Dibujos 
realizados con el movimiento de su cámara mientras se desplaza por la ciudad, fotografías que ella misma define como cortometrajes (Les Rencontres d'Arles, 2007, p. 86) por su prolongado tiempo de exposición. Un tiempo encerrado en una imagen que no representa los motivos fotografiados, que los vuelve invisibles al espectador y los transforma en líneas y colores sin vinculación con la impronta gráfica de la imagen fotográfica del instante decisivo. Se tratan de fotografías que pierden su vinculación de anclaje con el pasado, de recuerdo. Cuando se combinan las variables de tiempo de exposición prolongado y modificación del punto de anclaje de la cámara, el resultado es una fotografía que pierde su valor como representación naturalista de una escena, desaparece esa idea histórica de documento fidedigno con la realidad, se transforma en una amalgama de formas y luces difícilmente identificables. Imágenes complejas de decodificar por parte del espectador si no tiene suficientes conocimiento técnicos del medio fotográfico.

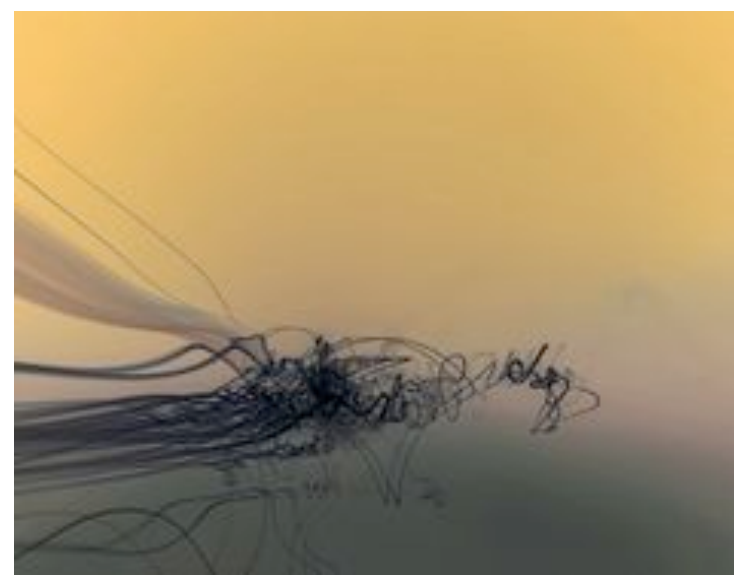

F3. Main Road E 75, Lapland, 2006. Fotografía de Nanna Hänninen (serie The New Landscapes)

No todos los casos de fotografías de exposición prolongada son tan extremos como los presentados anteriormente. Con frecuencia el tiempo de obturación se utiliza intencionalmente por parte del fotógrafo para producir una sensación de movimiento más corta y controlada en la imagen. El espectador sigue viendo en las fotografías elementos que comienzan a desparecer o estelas, pero su decodificación es mucho más sencilla. La fotógrafa Francesca 
Woodman utilizó está técnica para eliminar su rostro de algunas fotografías o potenciar la acción del movimiento dentro de sus autorretratos. En Space ${ }^{2}$ (1975-1978) (F4) se observa una imagen anónima emplazada en un espacio aséptico. En algunas imágenes sus rasgos faciales han desparecido mostrando el movimiento de su cabeza, en otras gran parte del cuerpo se desvanece mientras realiza una acción. Ocultar su identidad al espectador es uno de los temas recurrentes de Woodman, pero en este caso utiliza los recursos técnicos de la fotografía en lugar de volver su rostro o de taparlo con algún objeto. Se trata de una serie que profundiza en las posibilidades de representación que ofrece la técnica fotográfica. En la misma línea en la que se muestra un breve fragmento de tiempo está In Fujisan, $n^{o} 15$ (2001) de Rong Rong y Inri , donde el desvanecimiento de los cuerpos desnudo mostrados de manera intermitente escenifican el avance de la pareja al andar. También Titarenko utiliza la misma técnica en su serie City of Shadows (1992-1994), para mostrarnos una oscura y amarga San Petersburgo, como demuestra Untitled (Crowd 2) (F5) donde un inmenso conjunto de personas anónimas sube por unas escaleras en las que el espectador solo acierta a distinguir algunas manos y pies.

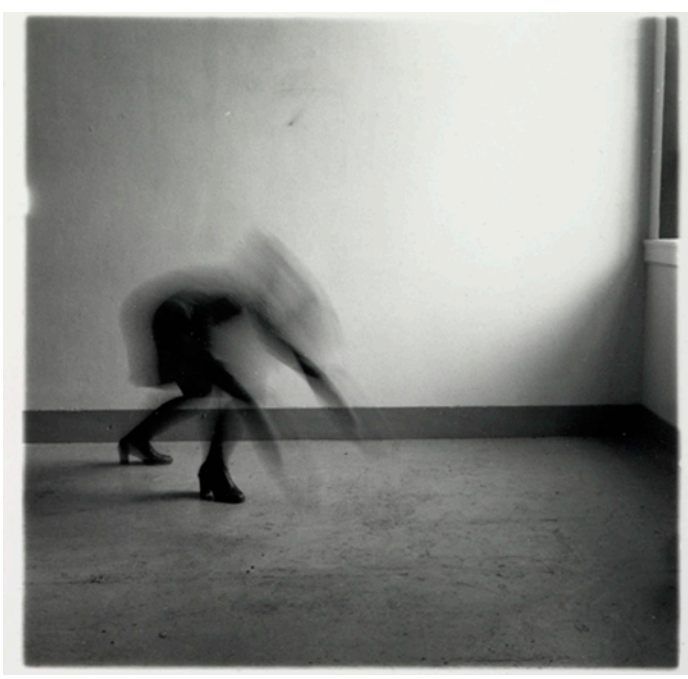

F4. Space2, Providence, Rhode Island, 19751978. Fotografía de Francesca Woodman.

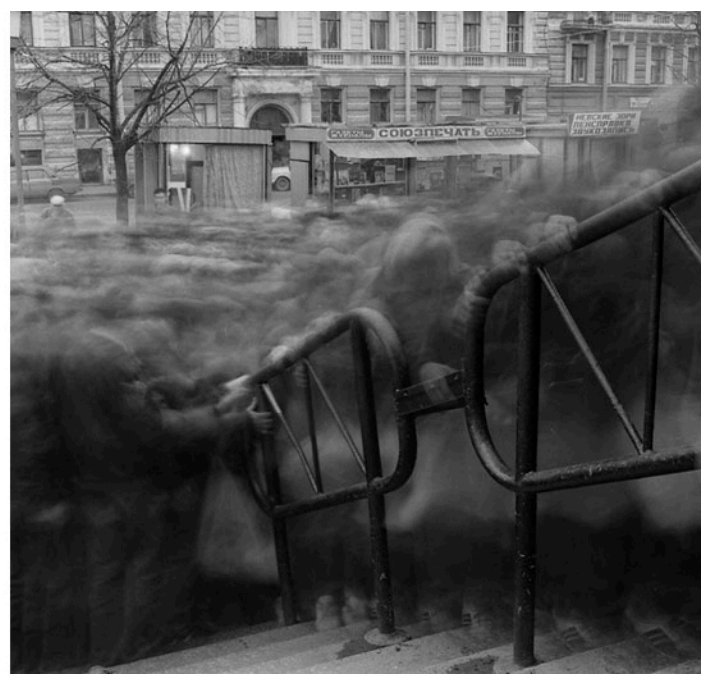

F5. Untitled (Crowd 2), San Petersburgo, 1993. Fotografía de Alexey Titarenko. 
En otros casos, la captura de un tiempo largo de exposición junto a cierto movimiento de cámara es utilizado por Michael Ackerman como una técnica para dotar de una expresión perturbadora a sus imágenes, muchas de su serie Departure (Poland > 1999-2007) lo demuestran. También varias de las imágenes de Stigmata (2004), realizadas por Antonie d'Agata, utilizan este efecto.

En su afán de conquistar el movimiento, la fotografía no tardó en convertirse en cronofotografía, primero gracias al revolver astronómico (1874) de Janssen, que utilizó para registrar el movimiento de los planetas, y después merced a los trabajos del fisiólogo francés Etienne-Jules Marey (1830-1904), que con su fusil fotográfico estudio primero el galope de los caballos, descompuesto en una serie de fotografías, y luego los movimientos de otros animales y del hombre (Gubern, 1971, p. 21).

Sería Marey el que conseguiría fijar sobre una sola imagen la descomposición del movimiento de un animal u hombre a lo largo de un periodo de tiempo. Esta forma de capturar el movimiento congela la imagen y prescinde de la estela causada por la abertura prolongada del obturador. Se superponen diferentes capturas del mismo sujeto en diferentes posiciones con lo que se consigue desgranar paso a paso el movimiento. Herold Edgerton iría aún más lejos, consiguiendo un efecto similar pero mucho más ajustado con el uso de un flash de gran intensidad lumínica. En este caso, el obturador permanece abierto durante los diferentes disparos sucesivos del flash que consiguen congelar el movimiento en diferentes etapas. Se obtiene una sucesión de posiciones bajo una misma imagen logrando desfragmentar el tiempo en varios pasos. La diferencia estética con respecto a la técnica anteriormente mencionada utilizada por fotógrafos como Woodman o Titarenko es evidente, mientras estos consiguen estelas que deforman los sujetos en la cronofotografía, el sujeto fotografiado permanece congelado y su movimiento fragmentado en diversas etapas, las mismas en las que se ha disparado el flash. 


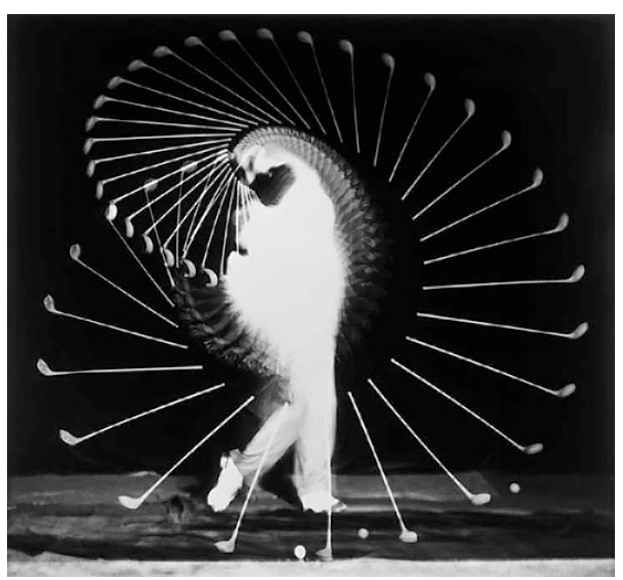

F6. Golfer Densmore Shute tees off at 10o flashes/second, 1938. Fotografía de Harold Edgerton

Todas estas imágenes funcionan como pequeños fragmentos de tiempo. Muestran una realidad en movimiento alejada de la estética más extendida del instante fotográfico. No solo consiguen mostrar un hecho, también representan una elipsis temporal. Sin embargo, su relación con el loop termina ahí. Al no reproducirse la acción de manera repetida a lo largo del tiempo, no podríamos hablar de loop como tal, si no de una acción, breve en estos casos, que se reproduce de un solo vistazo por parte del espectador. El momento queda condensado en una sola imagen, atemporal, que puede ser observada durante todo el tiempo que el espectador decida, pero nunca de manera repetida. Se obtendría un sample temporal inmóvil y fijo.

¿Sería posible mostrar un loop en una imagen fotográfica? Al observar la obra de artistas como Diego Vivanco o Marcelo Ciceri descubrimos imágenes que dependiendo de la posición y el movimiento de la cabeza del espectador reproducen una sensación de movimiento. Se trata de imágenes lenticulares, fotografías en este caso, que permiten mostrar sensación de tridimensionalidad, una sucesión de imágenes o una breve acción sucedida en el tiempo de manera continua a gusto del espectador. El proceso funciona de la siguiente manera:

Las imágenes lenticulares han existido desde que terminó la Segunda Guerra Mundial, cuando el desarrollo tecnológico de los plásticos hizo posible la fabricación de la lamina acanalada que se encuentra en la parte superior de 
cada imagen capaz de representar el movimiento e imagen estereoscópica. Estas láminas acanaladas se denominan lentes u hojas lenticulares porque en realidad son decenas de lentes ópticas cilíndricas situadas de forma paralela en la parte superior de unas imágenes preparadas de manera espacial. Las lentes refractan las imágenes situadas debajo de ellas por lo que a medida que el punto de vista cambia, la imagen percibida también cambia, creando la ilusión de movimiento (Lake, 1999).

En realidad no se trata de una imagen, si no de una sucesión de imágenes tratadas según distintos patrones y combinadas en una misma imagen. La sensación de movimiento de este conjunto de imágenes es visible gracias a la pantalla que las cubre; nos permite verlas de manera sucesiva, creando la sensación de movimiento o de tridimensionalidad.

Si entendemos la imagen lenticular como una sola imagen se puede entender que sí, que la posibilidad de visionado en loop es posible siempre que haya una intención por parte del espectador, acompañándola, por ejemplo, con su movimiento al contemplar la imagen. Sin embargo, si lo entendemos como un conjunto de imágenes tratadas y percibidas tras un dispositivo específico, estaríamos ante una moderna máquina de pre cine, siendo la imagen fotográfica parte de la construcción de ésta.
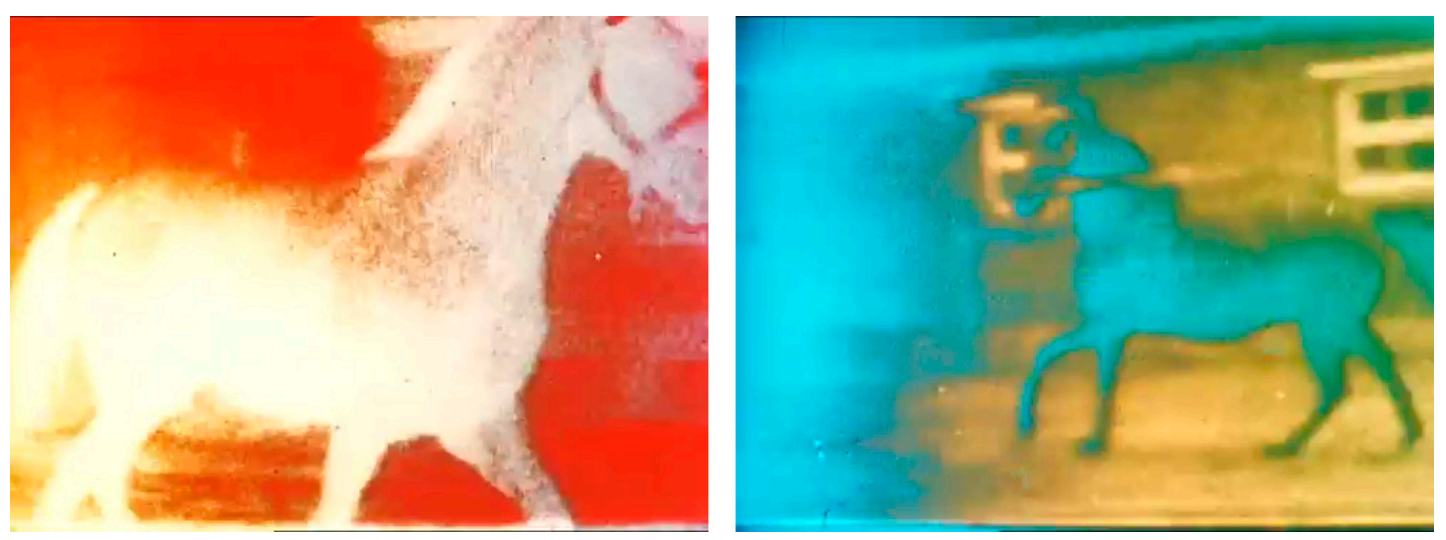

F7. Berlin Horse (1979) de Malcom Le Grice. Fotogramas de la película 


\subsection{La construcción temporal en base al sample}

El primer precedente del loop ligado a la imagen en movimiento lo podemos encontrar en las máquinas del pre cine: el fenaquistiscopio, el praxinoscopio o el zootropo conseguían mostrar imágenes animadas en loop, es decir, las acciones que se repetían constantemente hasta que el espectador dejaba de activar la maquinaria y la animación se detenía.

Esta idea de construcción temporal formada a partir de pequeñas unidades repetidas en continuidad será utilizada por el cine estructural para el desarrollo de su discurso cinematográfico. Las obras realizadas bajo estos planteamientos huyen del guión, desaparece la narración para ofrecernos una experiencia cinematográfica en crudo, sin artificios. "Es un cine de estructuras en el que la forma de toda la película está predeterminada y simplificada, y es esta forma la impresión fundamental de la película” (Sidney, 2000, p. 327). El lenguaje desarrollado por los cineastas estructurales fue el causante de que, pasados unos años, otros directores criticaran estas piezas por esnobismo académico y cine perezoso, (Zedd, 1984) debido en gran medida a su escaso componente lúdico. Estas obras no destacan por la espectacularidad de sus imágenes ni por las historias que cuentan. Son piezas que, en su mayoría, no resultan cómodas de ver y que hacen que su audiencia sea muy restringida y se mantenga al margen de la industria cinematográfica. "Los directores estructuralistas asumieron que el público de sus películas debía ser íntimo, un grupo sabio de cineastas.” (Dixon y Foster, 2002). Los cineastas estructuralistas son conscientes de que su obra será contemplada por un reducido número de espectadores, generalmente formados teóricamente sobre este movimiento, lo que les facilita la comprensión de las películas. No son piezas realizadas para públicos masivos, ni para ser proyectadas en salas comerciales de cine. $\mathrm{Su}$ sitio se encuentra en la intimidad de un museo o de una galería.

Como se ha comentado con anterioridad, de las características del cine estructural presentado por Sidney, este estudio se centrará en aquellas obras que utilizan el loop como construcción temporal. Malcom Le Grice cita tres 
posibles tipos de loop. Aquellos creados en el proyector, los loops copiados en una película de manera continua y aquellos que son modificados por lo que no respetan la continuidad rítmica de la repetición del loop (Le Grice, 1977. p. 108). Esta acción temporal que forma la base del segmento fílmico que se repetirá en bucle es similar a la representada en una fotografía en la que se registra el paso del tiempo como hemos comprobado anteriormente. Estas fotografías y el segmento cinematográfico encierran un espacio temporal limitado y mostrado ante el espectador, el sample representa un tiempo acotado, una acción en el tiempo. Sin embrago, las diferencias surgen en el momento de la reproducción. Mientras la acción de la fotografía se muestra instantáneamente, la repetición del segmento cinematográfico en loop conlleva un espacio temporal determinado y a su vez creará una ficción temporal que nunca ha existido.

Un ejemplo que demuestra esta creación temporal es la pieza de Le Grice Berlín Horse (1970) (F7). Se trata de una escena en la que un caballo da vueltas alrededor de una jinete. Este sample es mostrado con constantes variaciones: centrándose en detalles, deformando la perspectiva o añadiendo distintos efectos de color que degradan la imagen, a la vez que profundiza en la importancia del tiempo y aspectos temporales en el cine comparado con la pintura (McMahon, 2006). La pieza se entiende como una prolongación temporal de la acción, el espectador lo percibe como un todo no como una sucesión repetitiva. A su vez la obra puede ser entendida como un reflejo visual de su banda sonora, realizada también mediante loops por Brian Eno. Joyce Wieland utiliza en 1933 (1967) el mismo sistema que Le Grice pero, en este caso, las diferencias entre unos segmentos del loop y otros se encuentran en la velocidad a la que proyecta los fotogramas, de manera que el sample no es similar del todo.

La acción repetida sin modificaciones la encontramos en Film in Wich There Appear Edge Lettering, Sproket Holes, Dirt Particles, etc (1965-1966) de George Landow, realizada con un trozo de película que la casa Kodak utiliza como test de color. Durante 6 minutos, se proyecta este trozo de acetato en el 
que sólo aparecen animadas algunas letras recortadas por las perforaciones. La sensación de que la muestra no varía durante el bucle se rompe, ya que la película se desplaza ligeramente de manera horizontal durante la proyección, hecho que, junto a la suciedad acumulada sobre el acetato fílmico, hace que desparezca la idea de imagen estática y a su vez surja la idea de que la película tiene un tiempo propio creado a partir de la suma de la repetición del sample.

Paul Sharits en Piece Mandala End War (1966) utiliza dos elementos del cine estructural marcado por Sitney: la repetición en loop, en este caso sin tratarse de imágenes secuenciales, y el efecto de parpadeo en la proyección. La constante repetición de las imágenes unido al repetido parpadeo y a los efectos de la persistencia retiniana convierten la sensación de movimiento en una dura experiencia visual que, de nuevo, no se percibe como aislada, sino como continuada a lo largo de la duración de la pieza.

La herencia del cine estructural podemos encontrarla en la actualidad en piezas de diferente naturaleza. Un ejemplo sería el vídeo musical Imitation of Life (2001), de la banda americana R.E.M. y dirigido por Garth Jennings. Se trata de una pieza colorista que repite en loop los cerca de 20 segundos de duración total del sample original. Sin embargo, la sensación que tiene el espectador es que está viendo una pieza continua, rodada en un sólo plano estático. Los más de 30 personajes que aparecen en escena interpretan partes distintas de la canción. Mediante zooms realizados en postproducción, y una reproducción hacia delante y hacia atrás de la película, el director selecciona el personaje o acción que le interesa. Cuando el hecho seleccionado termina, vuelve a seleccionar otro trozo de pantalla, centrándose en una acción distinta y discriminando el resto del plano. Así sucesivamente. De un solo plano, y gracias a los zooms y loops, consigue crear un tiempo expandido que el espectador percibe como continuo, pero que en realidad dura solo 20 segundos.

Otras películas, como las recientes obras de Ken Jacobs, artista que realizó algunas de las películas más importantes del movimiento en la década de los 
60, continúan investigando las relaciones temporales en la imagen en movimiento pero desde la tecnología digital. Capitalism_ Slavery (2006) presenta imágenes estereográficas de la época victoriana, manipuladas digitalmente. Estas fotografías, al ser visionadas desde el estereoscopio, producen una sensación de tridimensionalidad. El sample utilizado en la película consiste en la combinación de estas imágenes, creando la sensación de movimiento de cámara. El objeto permanece inmóvil mientras la cámara se desplaza alrededor suyo por un instante. El efecto es similar al producido por una imagen lenticular visionada numerosas veces. De hecho parece una conversión a vídeo de ésta. El resultado es un efecto híbrido entre imagen fotográfica y vídeo.

Las tecnologías digitales están permitiendo nuevas reinterpretaciones y modificaciones de material analógico y Capitalism_Slavery sirve como puente para vincular imagen fija, especio temporal e imagen en movimiento. Esta pieza parte de una fotografía con vocación estática, sin movimiento, pero capaz de presentar un espacio en tres dimensiones, y que al pasarse a un formato cinemaográfico logra mostrar un breve espacio de tiempo y una acción determinada, en este caso un movimiento de cámara.

Esta necesidad de "mover" la imagen fija se materializa en la obra de algunos artistas como Rino Stefano Tagliafierro y su película Beauty (2014), en la que dota de acción y, por lo tanto, de tiempo a varias obras pictóricas clásicas. $\mathrm{O}$ en la nueva posibilidad que incluyen los teléfonos de Apple, Iphone 6s, conocida como Live Photo, consistente captar los instante anteriores y posteriores al hacer una fotografía. En realidad se trata de un vídeo dentro de una imagen. La fotografía se visualiza como estática, pero, al pulsar sobre ella, vemos la escena fotografiada animada, reproduciendo unos instantes anteriores y posteriores a los realizados con la fotografía. Mientras pulsemos la pantalla, la reproducción se realiza en modo de loop, obteniendo un vídeo de duración variable aunque el sample siempre tenga una duración fija. Boomerang, la nueva aplicación para móviles diseñada por el equipo de Instagram, la red social construida en base a compartir imágenes, tiene un 
funcionamiento muy similar. El usuario realiza una serie de fotografías consecutivas con el móvil y el software automáticamente lo transforma en un sample sobre el cual construye un loop continuo desplazando la acción de adelante atrás, listo para compartir en las redes sociales. Esta idea de breve animación digital repetida en modo constante no es nueva, y lleva años gestándose en la red. El GIF animado es la representación del loop por definición, un formato de imagen digital capaz de reproducir imagen secuencial que está inundando las redes sociales, se calcula que unas 23 millones de pequeñas animaciones son colgadas diariamente en Tumblr o enviadas a través de Facebook (Plambeck, 2015). Pequeñas animaciones que se están convirtiendo en un negocio y que nos hacen mirar de nuevo a las máquinas del pre cine, donde imágenes fijas se convertían en imágenes en movimiento presentando acción de manera continuada, en modo de loop, aquellas donde empezó todo.

\section{Conclusiones}

El interés por fijar la imagen reflejada en la cámara obscura sobre un soporte de manera que ésta se mantega estable ha ido acompañada con la idea de representar el movimiento. Una necesidad que a su vez creaba otra la de representar el espacio y el tiempo.

Se han visto diferentes maneras de representar el tiempo en la imagen fija, incluso diferentes maneras de representar periodos concretos en una sola imagen. Ejemplos que parten desde la imagen totalmente abstracta, a la creación de estelas que dibujan el movimiento continuo en el tiempo a otras que lo representan de manera escalonada. Distintos modelos que otorgaban a la imagen usos y aplicaciones muy diferentes, como el estudio científico o la posibilidad de potenciar emociones.

Esta idea de representación de tiempo acotado nos permite asociarla a la idea de sample, en el campo visual el elemento base sobre el cual se construirá el loop. Sin embargo, los medios de representación son radicalmente diferentes; mientras en la imagen fija la elipsis de tiempo se presenta de un 
solo golpe de vista, en el cine se visualiza a lo largo de un tiempo determinado, medible y variable. Característica que convuerte al loop en una herramienta muy interesante para crear ficciones visuales en movimiento y lo aleja completamente de la práctica fotográfica -entendiendo ésta como una imagen aislada, no de una composición de varias fotografías-. Es cierto que ambas se construyen sobre representaciones temporales, pero el resultado visual es drásticamente diferente.

A pesar de esta diferencia, hoy en día es fácil encontrar híbridos entre estos dos tipos de medios, como son las imágenes lenticulares que, aunque no gozan de gran popularidad, siguen presentes en nuestro entorno tanto espacios artísticos como en displays publicitarios, o las Live Photos o Gifs animados que podemos ver a través de nuestros teléfonos móviles. Esta necesidad de representar un periodo concreto de tiempo, por lo general breve y conciso y que lo encontramos desde los orígenes de la fotografía y elementos del pre cine, sigue más vigente que nunca gracias las nuevas posibilidades que ofrece la tecnología digital. Hoy en día todos llevamos una cámara de fotos continuamente en el bolsillo, una máquina digital acoplada a nuestro teléfono móvil que simplifica y abarata la acción de capturar imágenes y que nos permite transmitirlas en tiempo real a través de nuestras redes sociales donde, al menos, se nos garantiza que estarán al alcance de nuestros contactos.

\section{Referencias bibliográficas}

Belting, H. (2000) The Theater of illusion. En Theaters/Hiroshi Sugimoto. New York: Sonnabend Sundell.

Cartier-Breson, H. (2003). El instante decisivo. El malpensante, $\mathrm{N}^{\mathrm{O}} 43$.

Collado, E. (2012). Paracinema: la desmaterialización del cine en las prácticas artística. Madrid: Trama.

De Deuve, T. (2013). El posado y la instantánea. La paradoja fotográfica. Concreta $\mathrm{N}^{\mathrm{O}} \mathrm{02}$, pp. 65-79.

Dixon, W. y Foster, G. (2002). Experimental cinema. The film reader. Londres: Routledge. 
Doanne, M.A. (2010). Tiempo real: la instantaneidad y el imaginario fotográfico. En VVAA. El tiempo expandido (pp.61-88). Madrid: La Fabrica.

Fontcuberta, J. (2010). La cámara de pandora. Barcelona: Gustavo Gili.

Gubern, R. (1971). Historia del cine vol.1. Barcelona: Lumen.

Lake, M. (1999). An Art Form That's Precise But Friendly Enough to Wink. The New York Times, 20/03/1999. Recuperado de http://www.nytimes.com/1999/05/20/technology/an-art-form-thats-precise-but-friendly-enough-to-wink.html

Le Gice, M. (1977). Abstract film and beyond. Gran Bretaña: The MIT Press.

Les rencontres d'Arles, (2007). Catálogo de exposición. Verona: Actes Sud.

McMahon, D. (2006). An analysis of the soundtrack in the work of Malcolm Le Grice. En Senses of cinema No 38. Recuperado de http://sensesofcinema.com/2006/on-movies-musicians-andsoundtracks/soundtrack_le_grice/

Plambeck, J. (2015). Daily Report: The GIF Start-Ups Fostering a Visual Language on Mobile. The New York Times, 4/8/2015. Recuperado de http://bits.blogs.nytimes.com/2015/o8/04/daily-report-the-gif-startups-fostering-a-visual-language-on-mobile/?_r=o

Sitney, P.A. (2000). Structural Film. En Sitney, P.A. (ed.) Film culture reader (pp. 326-350). New York: Cooper Square Press.

Schaeffer, J.M. (1990). La imagen precaria del dispositivo fotográfico. Madrid: Cátedra.

Talbot, W. (2003). El lápiz de la naturaleza. En Fontcuberta, J. (ed.) Estética fotográfica (pp.49-52). Barcelona: Gustiavo Gili.

Zedd, N. (1984). Manifesto for the Cinema of Transgression. En Underground Film Bulletin. Recuperado de http://feastofhateandfear.com/archives/zedd.html

Cómo citar: Roncero, R. (2016). "Vínculos de representación temporal entre la fotografía y el cine estructural: una reflexión en torno al loop". Fotocinema. Revista científica de cine y fotografía, $\mathrm{n}^{\mathrm{o}}$ 12, pp. 81-102. Disponible: http://www.revistafotocinema.com/ 